\title{
Off to a Good Start: The Early Development of the Neural Substrates Underlying Visual Working Memory
}

\author{
Allison Fitch ${ }^{\dagger}$, Hayley Smith ${ }^{\dagger}$, Sylvia B. Guillory and Zsuzsa Kaldy * \\ Department of Psychology, University of Massachusetts Boston, Boston, MA, USA
}

Current neuroscientific models describe the functional neural architecture of visual working memory (VWM) as an interaction of the frontal-parietal control network and more posterior areas in the ventral visual stream (Jonides et al., 2008; D'Esposito and Postle, 2015; Eriksson et al., 2015). These models are primarily based on adult neuroimaging studies. However, WWM undergoes significant development in infancy and early childhood, and the goal of this mini-review is to examine how recent findings from neuroscientific studies of early WWM development can be reconciled with this model. We surveyed 29 recent empirical reports that present neuroimaging findings in infants, toddlers, and preschoolers (using EEG, fNIRS, rs-fMRI) and neonatal lesion studies in non-human primates. We conclude that (1) both the frontal-parietal control network

OPEN ACCESS

Edited by:

Lionel G. Nowak,

Université Toulouse III - Paul Sabatier and Centre National de la Recherche

Scientifique, France

Reviewed by:

Luis J. Fuentes, University of Murcia, Spain

Emmanuel Procyk,

French Institute of Health and Medical

Research, France

*Correspondence:

Zsuzsa Kaldy

zsuzsa.kaldy@umb.edu

${ }^{\dagger}$ Co-first authors.

Received: 20 January 2016 Accepted: 02 August 2016

Published: 18 August 2016

Citation:

Fitch A, Smith H, Guillory SB and Kaldy Z (2016) Off to a Good Start: The Early Development of the Neural Substrates Underlying Visual Working Memory. Front. Syst. Neurosci. 10:68.

doi: 10.3389/fnsys.2016.00068 and the posterior cortical storage areas are active from early infancy; (2) this system undergoes focalization and some reorganization during early development; (3) and the MTL plays a significant role in this process as well. Motivated by both theoretical and methodological considerations, we offer some recommendations for future directions for the field.

\footnotetext{
Keywords: visual working memory, frontoparietal network, ventral stream, early development, neonatal lesions in primates, infants, preschoolers
}

\section{INTRODUCTION}

Working memory is a limited-capacity system for the maintenance and manipulation of information in service of ongoing tasks. The classic model of working memory (WM, Baddeley and Hitch, 1974) distinguishes the central executive system and two different sensory buffers for the temporary storage of visual and auditory information (an additional system, the episodic buffer, was later added: Baddeley, 1986). This multicomponent model has framed essentially all research on WM for more than 20 years. More recent "state-based" WM models (Cowan, 1988; Oberauer, 2002; McElree, 2006), however, question basic assumptions of the multicomponent model, claiming

Abbreviations: DR, delayed response; DNMS, delayed non-match to sample; DTI, diffusion tensor imaging; EEG, electroencephalography; fNIRS, functional near infrared spectroscopy; fMRI, functional magnetic resonance imaging; HR, heart rate; dlPFC, dorsolateral prefrontal cortex; LTM, long-term memory; MTL, medial temporal lobe; Neo-HC, neonatally lesioned in the hippocampus; Neo-PRh, neonatally lesioned in the perirhinal cortex; Obj-SO, object self-ordered pointing task; PRh, perirhinal cortex; rs-fMRI, resting state fMRI; SOMT, Serial Order Memory Task; VoE, Violation of Expectation; vlPFC, ventrolateral prefrontal cortex; VWM, visual working memory; WM, working memory. 
that there are no separate WM-specific storage systems in the brain; instead, representations held in WM are temporarily activated long-term memory (LTM) representations. According to this view, storage of sensory information involves posterior cortices; visual WM (VWM) representations, for example, have been localized in various stages of the ventral stream, starting in the occipital cortex (Harrison and Tong, 2009; Serences et al., 2009) and continuing to inferior temporal cortex (Miller et al., 1991). Maintenance and manipulation of WM representations (the functions of the central executive) depend upon a frontal-parietal network (Awh and Jonides, 2001; Curtis and D'Esposito, 2003), in particular, anterior insula, lateral prefrontal cortex (PFC), dorsal anterior cingulate cortex, and areas within and surrounding the intraparietal sulcus (Seeley et al., 2007).

This conceptualization of WM is grounded in an extensive body of neuroscientific research, the majority of which has been conducted with human adults (for reviews, see Jonides et al., 2008; D’Esposito and Postle, 2015; Eriksson et al., 2015). WM undergoes significant postnatal development, with farreaching consequences on cognitive development in general (Bull et al., 2008). Behavioral studies have shown that the ability to hold information in VWM emerges in infancy (Káldy and Leslie, 2003, 2005; Ross-Sheehy et al., 2003; Zosh and Feigenson, 2012), and gradually improves throughout childhood (Riggs et al., 2006; Cowan et al., 2010; Simmering, 2012) and adolescence (Isbell et al., 2015). It is outside of the scope of this mini-review to provide a comprehensive overview of the entire behavioral literature (see Kibbe, 2015; Cowan, 2016; Reynolds and Romano, 2016, in this Research Topic); instead, we will examine whether recent findings from neuroscientific studies of early VWM development can be fit into the adult model above.

We limit our focus to studies that examine VWM in the first 5 years of life. While there is an abundant fMRI literature on children older than 6-7 years of age (e.g., Geier et al., 2009; von Allmen et al., 2014), this method currently cannot be used with very young children, and here we focus on what is known about these mechanisms before this age. The studies reviewed here employ a variety of neurophysiological methods (primarily electroencephalography, EEG, and functional Near-Infrared Spectroscopy, fNIRS) in human infants and young children (Table 1) and lesions in young primates (Table 2).

Structural and functional brain development progresses in parallel. Both classic brain anatomical studies in synaptic density (Huttenlocher and Dabholkar, 1997) and more recent structural connectivity studies using DTI (Qiu et al., 2015) found a posterior-to-anterior progression during the first few years of life, with white matter developing in the occipital and temporal cortices before frontal areas. While our focus in this minireview is on the functional development of the system underlying VWM, we will also discuss a few groundbreaking studies where researchers were able to link behavioral performance in a VWM task with myelination of a specific network (Short et al., 2013; Meng et al., 2014).

\section{NEURODEVELOPMENT OF THE HUMAN VWM SYSTEM: INFANCY (0-2 YEARS)}

Many of the neuroimaging studies examining infant VWM development employed the classic A-not-B task in conjunction with optical imaging (fNIRS) or EEG. In this task, an object is hidden at one of two locations and the infant is allowed to manually search for it. Once the infant repeatedly succeeds at one location, the object is then hidden at the other location. In the looking-based version of this task, looking times to the two locations are contrasted.

In one of the first studies to measure regional blood-flow changes in infants using fNIRS, Baird et al. (2002) found that prefrontal cortex (PFC) activity increased with success on an object maintenance task. More recently, EEG power and coherence measures from the entire scalp have been used to examine VWM task-related and age-related changes in the frontal-parietal network of infants (Bell and Wolfe, 2007; Cuevas and Bell, 2011; Bell, 2012; Cuevas et al., 2012a,b,c). Cuevas et al. (2012a), for example, found that frontal EEG power and heart rate predicted VWM performance in infants at 10 months, but not at 5 months. In another study, successful performance on the A-not-B task was found to be related to increased frontalparietal coherence at 8 months (Bell, 2012; Cuevas et al., 2012b). These findings suggest that the frontal-parietal network supports successful VWM performance between 8 and 10 months.

During the infancy period, functional connectivity of the VWM network appears to become less diffuse with age. Cuevas et al. (2012a) found an increase in EEG coherence relative to baseline across the entire scalp in 5-month-olds but only between the medial frontal and occipital electrode sites in 10-montholds. This finding is additionally supported by the observation of increased focalization of frontal-parietal network activity between 8 months and 4.5 years of age, which may reflect more efficient communication (Bell and Wolfe, 2007).

Resting-state fMRI (rs-fMRI) has been used to identify functional connections between brain regions in the absence of any task. This latter aspect makes this method particularly attractive for studies of early development, as infants can be scanned during sleep. In a pioneering study, Alcauter et al. (2014) tracked the development of resting-state networks in infants from birth to 2 years of age and their VWM performance. In addition to significant gains in synchrony among prefrontal and parietal regions at age one, it was found that connectivity between the thalamus and the salience network (which includes the insula, the cingulate, and frontal cortices, and is considered a sub-network of the frontal-parietal network in adults, see Elton and Gao, 2014) at age one predicted VWM performance at age two. In a DTI tractography study, the same group found that myelination of the tracts connecting frontal and parietal cortices predicted VWM performance in 1-year-old infants (Short et al., 2013). These studies thus corroborate the EEG findings that frontal-parietal connectivity is present before the end of the first year, and is related to VWM development. However, because salience network activity is functionally dissociated from WM performance in adults (Seeley et al., 2007; Elton and Gao, 2014), 


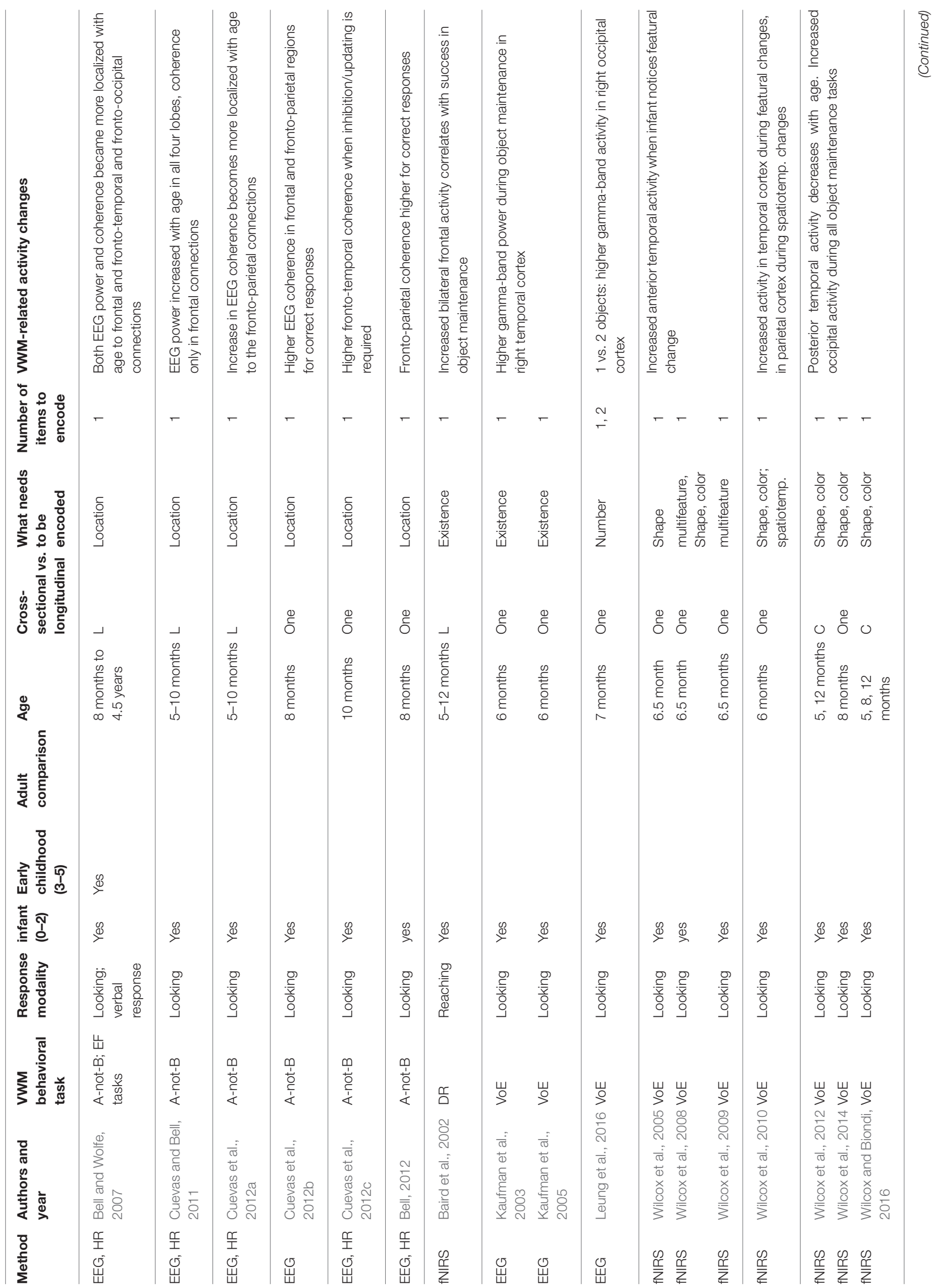


it is likely this network undergoes functional reorganization between toddlerhood and adulthood.

The involvement of posterior cortical areas in infant VWM has primarily been examined using more modern behavioral paradigms, such as Violation-of-Expectation (VoE), in conjunction with fNIRS, or EEG. Using fNIRS, Wilcox and colleagues found that the anterior temporal cortex showed consistent activation when infants noticed a change in the features of an object that they held in mind when it reappeared from behind an occluder (thus, this feature change "violated" their expectations; Wilcox et al., 2005, 2008, 2009, 2010, 2014). Task-related activation in the posterior temporal cortex gradually decreased from 5 to 12 months, and the occipital cortex was active during all object maintenance tasks. This decrease in activation in posterior temporal cortex may reflect functional reorganization of object processing areas over the course of development (Wilcox et al., 2012, 2014; Wilcox and Biondi, 2016). Converging evidence for maintenance related activity in posterior storage areas has been reported by Kaufman et al. (2003, 2005) using EEG. They found that increased gamma-band (20$60 \mathrm{~Hz})$ activity in the right temporal cortex of 6-month-olds was associated with the maintenance of object representations behind an occluder (Kaufman et al., 2003, 2005). More recently, Kaufman and colleagues showed that the same response was higher in the right occipital cortex when infants kept two vs. one object in VWM (Leung et al., 2016). This result raises the possibility of finding a load-dependent neural signature of information storage in infant VWM.

In sum, the literature concerning the neural substrates of VWM systems in infants points toward an early emerging frontal-parietal network; one that is present and active even before age one (Bell, Cuevas; connectivity studies). Studies by Wilcox, Kaufman and their colleagues found storage-related VWM activity in the temporal and occipital cortices as well, which may mirror similar findings in adults in the ventral visual stream (for a recent review, see Lee and Baker, 2016).

\section{NEURODEVELOPMENT OF THE HUMAN VWM SYSTEM: EARLY CHILDHOOD (3-5 YEARS)}

To date, only a handful of neuroimaging studies have examined VWM during the early childhood period, and all used fNIRS. The lack of neuroimaging (both structural and functional) conducted with this notoriously challenging age range is primarily due to practical limitations: Preschool-age children require special experimental designs as they are rarely willing to participate for an extended time, and they often do not follow verbal instructions reliably. One notable limitation of three of the four fNIRS studies reviewed below is that hemodynamic responses were measured only in the frontal areas (or in Buss et al., 2014, in the frontal and the parietal cortices). Thus, conclusions were necessarily constrained to these regions.

Tsujimoto et al. (2004) found that lateral PFC activity in 5.5year-old children was very similar to adults' during a change detection task: One of the most widely used paradigms in adult 


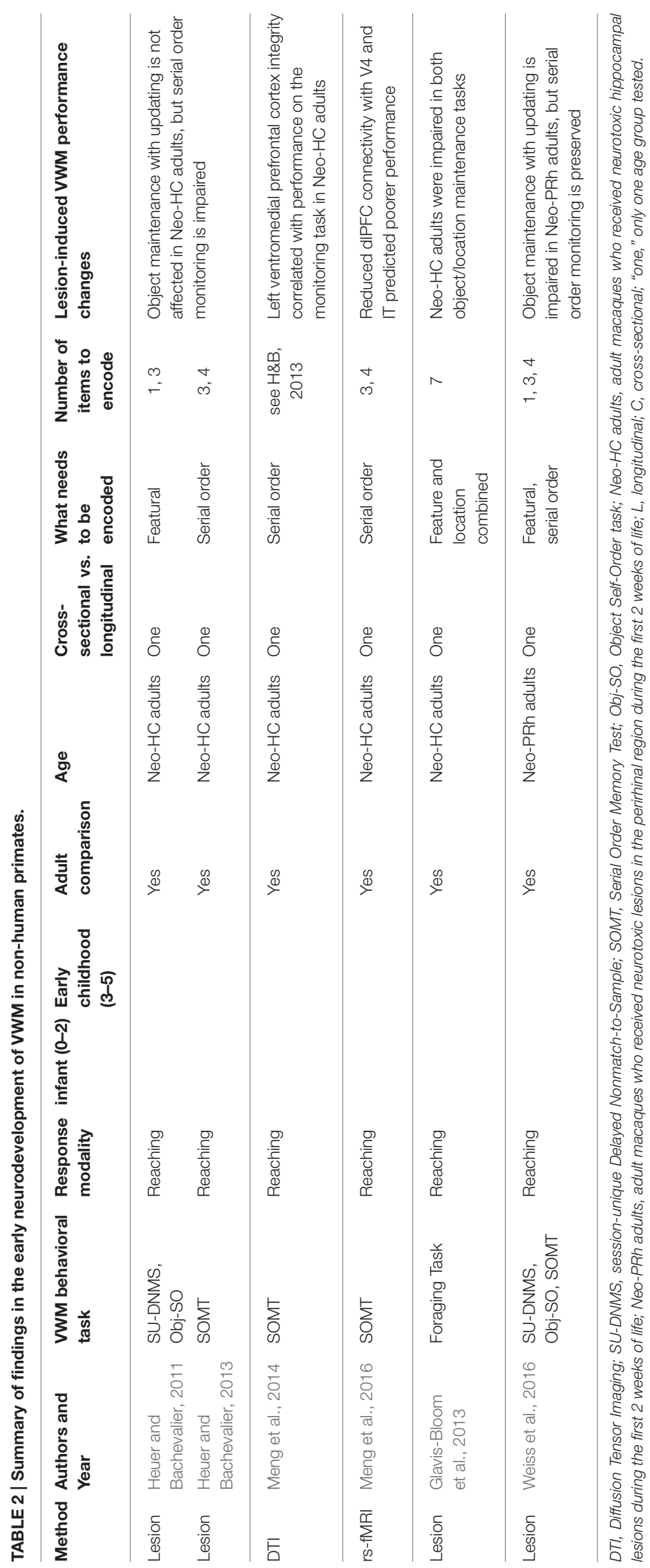


VWM research, participants are briefly presented with a set of to-be-remembered items, and following a short delay are tested on whether or not the items have changed (Pashler, 1988; Luck and Vogel, 1997). Using the same task with a small longitudinal sample, Tsujii et al. (2009) found that between 5 and 7 years of age, increased VWM performance correlated with right lateralization of frontal activity.

More recently, Buss et al. (2014) found that the frontalparietal network was active in 3- and 4-year-olds during a change detection task, where load was systematically manipulated. Overall, they demonstrated greater involvement of parietal cortical areas relative to frontal areas, as well as increased parietal activity in 4-year-olds relative to 3-year-olds. Prior studies found that, in adults, activity in the parietal cortex was load-dependent for small set sizes, and leveled off at the behaviorally-defined capacity limit (Todd and Marois, 2004; Palva et al., 2011). In 3and 4-year-olds this activity was load-dependent, but continued to increase beyond the observed capacity limit-a finding that warrants further investigation. In a similar investigation of delaydependent activity, Perlman et al. (2016) manipulated the length of delays ( 2 vs. $6 \mathrm{~s}$ ) and found age-dependent activation in lateral PFC in children between 3 and 7 years of age, and that children recruited this area more during longer delays. As the ventrolateral PFC is involved in maintenance, this finding suggests increased active rehearsal of information with age.

In sum, it appears that the frontal-parietal network becomes increasingly adult-like throughout early childhood. Increased recruitment of prefrontal and parietal areas point to increased focalization of the frontal-parietal system, while increased lateralization to the right hemisphere suggests adult-like specialization of this network for visuospatial tasks (Thomason et al., 2009). Because recordings were not made from the temporal and occipital areas, at the current time we cannot draw any conclusions about the involvement of the posterior cortices. The paucity of research in this age range creates a gap in our understanding of the development of VWM.

\section{NEURODEVELOPMENT OF THE NON-HUMAN PRIMATE VWM SYSTEM: EFFECTS OF NEONATAL LESIONS}

Both the frontal-parietal network and the posterior storage areas (e.g., IT) have multiple connections to the medial temporal lobe (MTL; Lavenex et al., 2002). While most current neuroscientific methods used in young children (fNIRS, EEG) do not allow access to these deep structures, primate lesion studies have provided a wealth of findings about the role of these structures in early development. Unlike adult lesion studies, which can only provide information about the relative contribution of a brain structure in a fully-formed system, neonatal lesion studies have the advantage of examining the downstream effects of a lesion on the developing system ${ }^{1}$. In the following section, we will focus on

\footnotetext{
${ }^{1}$ The earliest neuroscientific studies of the development of the frontal cortex used these techniques as well (Goldman, 1971; Miller et al., 1973), and demonstrated the role of both the dorsolateral and the ventrolateral PFC (dIPFC and vlPFC) in VWM. By connecting findings in PFC-lesioned macaques and human infants, Diamond and Goldman-Rakic (1989) laid the one of the first building blocks of developmental cognitive neuroscience.
}

the role of the MTL in the development of the frontal-parietal network.

Heuer and Bachevalier (2011) examined the contribution of the hippocampus to the development of VWM abilities. Here they utilized a delayed response task (also widely used in classic behavioral studies with infants; e.g., Diamond and Doar, 1989), where participants are presented with one object (the sample), followed by a delay, and then a choice between a matching object and a non-matching object. In the delayed-nonmatch-to-sample (DNMS) version of this task, participants are rewarded for selecting the non-matching object. Results showed that adult macaques that received neonatal hippocampal lesions (henceforth: Neo-HC) performed as well as sham-operates on a DNMS task (requires maintenance and putatively relies on the vlPFC, see Petrides, 1995). However, these macaques failed to even meet training criterion on an object self-ordered pointing task (Obj-SO) in which participants selected baited food wells in a different order on successive trials (requires manipulation, specifically, monitoring serial order, and putatively relies on the dlPFC; Petrides, 1995).

Follow-up studies using other dlPFC-associated VWM tasks have provided supporting evidence: Neo-HC macaques made significantly more errors than controls on a serial-order memory (SOMT) task (Heuer and Bachevalier, 2013), and in a foraging task were more likely than controls to return to boxes they had already visited, especially if that box previously contained the animal's preferred food (Glavis-Bloom et al., 2013). Thus early hippocampal lesions lead to deficits in VWM manipulation, but not in maintenance. The finding that early hippocampal damage leads to deficits on a task that taps dlPFC has been replicated in human patients who suffered hypoxic-ischaemic events early in life (Geva et al., 2016).

In addition to hippocampal lesions, Weiss et al. (2016) found that neonatal lesions to another area of MTL, the perirhinal cortex, impacted VWM performance on tasks believed to rely on the vlPFC. In their study, macaques with neonatal lesions of perirhinal cortex (Neo-PRh) were impaired on a DNMS task at short delays, as well as an Obj-SO task; both repeated stimuli across trials, and thus required trial-to-trial updating of information in VWM. In contrast, Neo-PRh animals performed well on a task that used novel stimuli across trials (SOMT), thus did not require updating, suggesting that the perirhinal cortex is not involved in manipulation of WM contents per se, but rather interference resolution or associated executive functions (e.g., inhibition).

These findings suggest that the MTL gives rise to the development of PFC-associated VWM skills, such as manipulation and interference resolution, likely through reciprocal neuroanatomical connections (Goldman-Rakic et al., 1984; Aggleton et al., 2015). Two recent connectivity studies provide converging evidence for this. Early hippocampal damage led to both reduced white matter (Meng et al., 2014) and decreased resting-state connectivity (Meng et al., 2016) between the dIPFC and the medial PFC and several posterior areas, such as IT and V4, in adult macaques. These anatomical and functional impairments correlated with poorer performance on the SOMT (Meng et al., 2014, 2016). This correlation underscores the importance of the hippocampus, as well as the frontal-parietal network in the development of VWM 
abilities: By adulthood, Neo-HC macaques had not developed compensatory mechanisms for VWM. This stands in stark contrast to a similar neonatal lesion study demonstrating compensatory mechanisms for rule learning and recognition memory following lesions to the vlPFC (Malkova et al., 2016).

\section{SUMMARY AND FUTURE DIRECTIONS}

The goal of this mini-review was to examine the neurophysiological evidence regarding the early emergence of the VWM network that involves both the frontal-parietal control network and the posterior storage areas that have been identified in adults. Our first conclusion is that both of these systems seem to be active from as early as the second half of the first year in humans.

A handful of longitudinal and cross-sectional studies reviewed here point to a gradual focalization of the frontal-parietal system throughout development (see the works of Bell and her colleagues). We also see some evidence for the functional reorganization of the network during the early life period: for example, a shift away from the salience network from infancy to adulthood (Alcauter et al., 2014), and increasing reliance on the parietal cortex during the preschool years (Buss et al., 2014). These changes may reflect a specialization within the network. Furthermore, findings from non-human primates have demonstrated the significance of the medial temporal lobe in the development of the lateral PFC (see the works of Bachevalier and her colleagues).

Related to the emergence of posterior information storage areas, a number of studies found object-maintenance related activity in both occipital and temporal lobes in infancy (see the works of Kaufman and his colleagues). Studies on VWM mechanisms in early childhood have not recorded from these posterior areas, so our understanding of how these areas support VWM in this age range is, at the moment, limited.

A defining characteristic of VWM is its limited capacity. This functional characteristic can serve as a signature to identify VWM storage-related mechanisms: In these structures, activity is expected to gradually increase with the number of to-beremembered items, and then remain constant when capacity limit has been reached (e.g., Palva et al., 2011). In studies that aim to find this signature, the adult cognitive neuroscience literature has adopted a useful psychophysical measure to quantify VWM capacity (Cowan's $k^{2}$ ). Research on school-age children has recently begun to examine how memory load affects the recruitment of different parts of the VWM system using this measure (e.g., Shimi et al., 2014; Kharitonova et al., 2015). Importantly, this approach has already been applied successfully in preschoolers (Buss et al., 2014, reviewed above).

${ }^{2}$ The formula is $k=\mathrm{N}^{*}(\mathrm{H}+\mathrm{CR}-1)$, where $\mathrm{N}$ is the number of items presented, $\mathrm{H}$ is hit rate, $\mathrm{CR}$ is correct rejection rate (Cowan et al., 2005).

\section{REFERENCES}

Aggleton, J. P., Wright, N. F., Rosene, D. L., and Saunders, R. C. (2015). Complementary patterns of direct amygdala and hippocampal projections
Based on both theoretical and methodological considerations, the ideal design to study neurodevelopmental change in the VWM system has the following attributes:

(a) Uses the same behavioral task across ages from infants to adults (or at least between infants and young children or young children and older ones).

(b) Quantifies capacity behaviorally (e.g., with Cowan's $k)$, and measures neural activity as a function of capacity, in order to identify storage-related mechanisms.

(c) Uses a longitudinal sample, to minimize the effects of interindividual variability.

Some of the studies to date have two of these features, but none have all three. Because of its versatility and low task demands, the change detection paradigm is the best positioned to meet criterion (a) in the near future. Thus, a crucial open question for future studies is how neural activity in the VWM network changes in children under 3 years of age using this task. As well, future studies with preschool-age children that record from posterior cortices (using whole-brain nets, see e.g., Sato et al., 2012) should elucidate the role of these structures in VWM beyond infancy.

Despite all the methodological challenges that are involved in studying brain functions in infants, young children, and young primates, research on early VWM neurodevelopment has gotten off to an exciting start. Several different physiological methods have already yielded converging results, and recent advances in neuroimaging methods (e.g., Cutini and Brigadoi, 2014; Graham et al., 2015), will likely lead to an expansion of research in the near future. We look forward to an exciting period in the study of the early developmental unfolding of the VWM system.

\section{AUTHOR CONTRIBUTIONS}

$\mathrm{AF}$ and HS contributed equally to this manuscript by selecting and summarizing relevant studies and writing multiple sections of this review. SG contributed significantly to the section on EEG and rs-fMRI studies. ZK has developed the theoretical perspective with the help of AF and HS. All four authors contributed to the writing and editing of the paper.

\section{FUNDING}

The authors were supported by National Institutes of Health's grant R15HD086658 and a Seed Grant from the Simons Foundation under the auspices of the Simons Center for the Social Brain at MIT (\#319294) awarded to ZK.

to the macaque prefrontal cortex. Cereb. Cortex 25, 4351-4373. doi: 10.1093/cercor/bhv019

Alcauter, S., Lin, W., Smith, J. K., Short, S. J., Goldman, B. D., Reznick, J. S., et al. (2014). Development of thalamocortical connectivity during infancy and its 
cognitive correlations. J. Neurosci. 34, 9067-9075. doi: 10.1523/JNEUROSCI. 0796-14.2014

Awh, E., and Jonides, J. (2001). Overlapping mechanisms of attention and spatial working memory. Trends Cogn. Sci. 5, 119-126. doi: 10.1016/S13646613(00)01593-X

Baddeley, A. D. (1986). Working Memory. Oxford Psychology Series \#11. Oxford: Clarendon Press.

Baddeley, A. D., and Hitch, G. (1974). "Working memory”, in The Psychology of Learning and Motivation, Vol. 8, ed G. H. Bower (New York, NY: Academic Press), 47-89.

Baird, A. A., Kagan, J., Gaudette, T., Walz, K. A., Hershlag, N., and Boas, D. A. (2002). Frontal lobe activation during object permanence: data from nearinfrared spectroscopy. NeuroImage 16, 1120-1126.

Bell, M. A. (2012). A psychobiological perspective on working memory performance at 8 months of age: psychobiology of infant working memory. Child Dev. 83, 251-265. doi: 10.1111/j.1467-8624.2011.01684.x

Bell, M. A., and Wolfe, C. D. (2007). Brain reorganization from infancy to early childhood: Evidence from EEG power and coherence during working memory tasks. Dev. Neuropsychol. 31, 21-38. doi: 10.1080/87565640709336885

Bull, R., Espy, K. A., and Wiebe, S. A. (2008). Short-term memory, working memory, and executive functioning in preschoolers: longitudinal predictors of mathematical achievement at age 7 years. Dev. Neuropsychol. 33, 205-228. doi: 10.1080/87565640801982312.

Buss, A. T., Fox, N., Boas, D. A., and Spencer, J. P. (2014). Probing the early development of visual working memory capacity with functional near-infrared spectroscopy. Neuroimage 85, 314-325. doi: 10.1016/j.neuroimage.2013.05.034

Cowan, N. (1988). Evolving conceptions of memory storage, selective attention, and their mutual constraints within the human information processing system. Psychol. Bull. 104, 163-191.

Cowan, N. (2016). Working memory maturation: can we get at the essence of cognitive growth? Perspect. Psychol. Sci. 11, 239-264. doi: 10.1177/1745691615 621279

Cowan, N., Elliott, E. M., Scott Saults, J., Morey, C. C., Mattox, S., Hismjatullina, A., et al. (2005). On the capacity of attention: its estimation and its role in working memory and cognitive aptitudes. Cogn. Psychol. 51, 42-100. doi: 10.1016/j.cogpsych.2004.12.001

Cowan, N., Morey, C. C., AuBuchon, A. M., Zwilling, C. E., and Gilchrist, A. L. (2010). Seven-year-olds allocate attention like adults unless working memory is overloaded: capacity and attention allocation. Dev. Sci. 13, 120-133. doi: 10.1111/j.1467-7687.2009.00864.x

Cuevas, K., and Bell, M. A. (2011). EEG and ECG from 5 to 10 months of age: developmental changes in baseline activation and cognitive processing during a working memory task. Int. J. Psychophysiol. 80, 119-128. doi: 10.1016/j.ijpsycho.2011.02.009

Cuevas, K., Bell, M. A., Marcovitch, S., and Calkins, S. D. (2012a). Electroencephalogram and heart rate measures of working memory at 5 and 10 months of age. Dev. Psychol. 48, 907-917. doi: 10.1037/a 0026448

Cuevas, K., Raj, V., and Bell, M. A. (2012b). Functional connectivity and infant spatial working memory: a frequency band analysis: infant frequency bands and EEG coherence. Psychophysiology 49, 271-280. doi: 10.1111/j.14698986.2011.01304.x

Cuevas, K., Swingler, M. M., Bell, M. A., Marcovitch, S., and Calkins, S. D. (2012c). Measures of frontal functioning and the emergence of inhibitory control processes at 10 months of age. Dev. Cogn. Neurosci. 2, 235-243. doi: 10.1016/j.dcn.2012.01.002

Curtis, C. E., and D'Esposito, M. (2003). Persistent activity in the prefrontal cortex during working memory. Trends Cogn. Sci. 7, 415-423. doi: 10.1016/S13646613(03)00197-9

Cutini, S., and Brigadoi, S. (2014). Unleashing the future potential of functional near-infrared spectroscopy in brain sciences. J. Neurosci. Methods 232, 152-156. doi: 10.1016/j.jneumeth.2014.05.024.

D'Esposito, M., and Postle, B. R. (2015). The cognitive neuroscience of working memory. Ann. Rev. Psychol. 66, 115-142. doi: 10.1146/annurev-psych-010814015031

Diamond, A., and Doar, B. (1989). The performance of human infants on a measure of frontal cortex function, the delayed response task. Dev. Psychobiol. $22,271-294$
Diamond, A., and Goldman-Rakic, P. S. (1989). Comparison of human infants and rhesus monkeys on Piaget's AB task: evidence for dependence on dorsolateral prefrontal cortex. Exp. Brain Res. 74, 24-40.

Elton, A., and Gao, W. (2014). Divergent task-dependent functional connectivity of executive control and salience networks. Cortex 51, 56-66. doi: 10.1016/j.cortex.2013.10.012

Eriksson, J., Vogel, E. K., Lansner, A., Bergström, F., and Nyberg, L. (2015). Neurocognitive architecture of working memory. Neuron 88, 33-46. doi: 10.1016/j.neuron.2015.09.020

Geier, C. F., Garver, K., Terwilliger, R., and Luna, B. (2009). Development of working memory maintenance. J. Neurophysiol. 101, 84-99. doi: 10.1152/jn.90562.2008

Geva, S., Cooper, J. M., Gadian, D. G., Mishkin, M., and Vargha-Khadem, F. (2016). Impairment on a self-ordered working memory task in patients with early-acquired hippocampal atrophy. Dev. Cogn. Neurosci. 20, 12-22. doi: 10.1016/j.dcn.2016.06.001

Glavis-Bloom, C., Alvarado, M. C., and Bachevalier, J. (2013). Neonatal hippocampal damage impairs specific food/place associations in adult macaques. Behav. Neurosci. 127, 9-22. doi: 10.1037/a0031498

Goldman, P. S. (1971). Functional development of the prefrontal cortex in early life and the problem of neuronal plasticity. Exp. Neurol. 32, 366-387.

Goldman-Rakic, P. S., Selemon, L. D., and Schwartz, M. L. (1984). Dual pathways connecting the dorsolateral prefrontal cortex with the hippocampal formation and parahippocampal cortex in the rhesus monkey. Neuroscience 12, 719-743.

Graham, A. M., Pfeifer, J. H., Fisher, P. A., Lin, W., Gao, W., and Fair, D. A. (2015). The potential of infant fMRI research and the study of early life stress as a promising exemplar. Dev. Cogn. Neurosci. 12, 12-39. doi: 10.1016/j.dcn.2014.09.005

Harrison, S. A., and Tong, F. (2009). Decoding reveals the contents of visual working memory in early visual areas. Nature 458, 632-635. doi: 10.1038 /nature07832

Heuer, E., and Bachevalier, J. (2011). Neonatal hippocampal lesions in rhesus macaques alter the monitoring, but not maintenance, of information in working memory. Behav. Neurosci. 125, 859-870. doi: 10.1037/a0025541

Heuer, E., and Bachevalier, J. (2013). Working memory for temporal order is impaired after selective neonatal hippocampal lesions in adult rhesus macaques. Behav. Brain Res. 239, 55-62. doi: 10.1016/j.bbr.2012.10.043

Huttenlocher, P. R., and Dabholkar, A. S. (1997). Regional differences in synaptogenesis in human cerebral cortex. J. Comp. Neurol. 387, 167-178.

Isbell, E., Fukuda, K., Neville, H. J., and Vogel, E. K. (2015). Visual working memory continues to develop through adolescence. Front. Psychol. 6:696. doi: 10.3389/fpsyg.2015.00696

Jonides, J., Lewis, R. L., Nee, D. E., Lustig, C. A., Berman, M. G., and Moore, K. S. (2008). The mind and brain of short-term memory. Annu. Rev. Psychol. 59, 193-224. doi: 10.1146/annurev.psych.59.103006.093615

Káldy, Z., and Leslie, A. (2005). A memory span of one? Object identification in 6.5-month-old infants. Cognition 57, 153-177. doi: 10.1016/j.cognition.2004.0 9.009

Káldy, Z., and Leslie, A. M. (2003). Identification of objects in 9-month-old infants: integrating 'what' and 'where' information. Dev. Sci. 6, 360-373. doi: 10.1111/1467-7687.00290

Kaufman, J., Csibra, G., and Johnson, M. H. (2003). Representing occluded objects in the human infant brain. Proc. Roy. Soc. B Biol. Sci. 270, S140-S143. doi: 10.1098/rsbl.2003.0067

Kaufman, J., Csibra, G., and Johnson, M. H. (2005). Oscillatory activity in the infant brain reflects object maintenance. Proc. Natl. Acad. Sci. U.S.A. 102, 15271-15274. doi: 10.1073/pnas.0507626102

Kharitonova, M., Winter, W., and Sheridan, M. A. (2015). As working memory grows: a developmental account of neural bases of working memory capacity in 5- to 8-year old children and adults. J. Cogn. Neurosci. 27, 1775-1788. doi: 10.1162/jocn_a_00824

Kibbe, M. M. (2015). Varieties of visual working memory representation in infancy and beyond. Curr. Dir. Psychol. Sci. 24, 433-439. doi: 10.1177/096372141 5605831

Lavenex, P., Suzuki, W. A., and Amaral, D. G. (2002). Perirhinal and parahippocampal cortices of the macaque monkey: projections to the neocortex. J. Comp. Neurol. 447, 394-420. doi: 10.1002/cne.10243 
Lee, S. H., and Baker, C. I. (2016). Multi-voxel decoding and the topography of maintained information during visual working memory. Front. Syst. Neurosci. 10:2. doi: $10.3389 /$ fnsys. 2016.00002

Leung, S., Mareschal, D., Rowsell, R., Simpson, D., Iaria, L., Grbic, A., et al. (2016). Oscillatory activity in the infant brain and the representation of small numbers. Front. Syst. Neurosci. 10:4. doi: 10.3389/fnsys.2016.00004

Luck, S. J., and Vogel, E. K. (1997). The capacity of visual working memory for features and conjunctions. Nature 390, 279-281.

Malkova, L., Alvarado, M. C., and Bachevalier, J. (2016). Effects of separate or combined neonatal damage to the orbitofrontal cortex and the inferior convexivity on object recognition in monkeys. Cereb. Cortex 26, 618-627. doi: 10.1093/cercor/bhu227

McElree, B. (2006). "Accessing recent events," in The Psychology of Learning and Motivation, Vol. 46, ed B. H. Ross (San Diego, CA: Academic Press), 155-200.

Meng, Y., Hu, X., Bachevalier, J., and Zhang, X. (2016). Decreased functional connectivity in dorsolateral prefrontal cortical networks in adult macaques with neonatal hippocampal lesions: Relations to visual working memory deficits. Neurobiol. Learn. Mem. doi: 10.1016/j. nlm.2016.04.003. [Epub ahead of print].

Meng, Y., Payne, C., Li, L., Hu, X., Zhang, X., and Bachevalier, J. (2014). Alterations of hippocampal projections in adult macaques with neonatal hippocampal lesions: a diffusion tensor imaging study. NeuroImage 102, 828-837. doi: 10.1016/j.neuroimage.2014.08.059

Miller, E. A., Goldman, P. S., and Rosvold, H. E. (1973). Delayed recovery of function following orbital prefrontal lesions in infant monkeys. Science 182, 304-306.

Miller, E. K., Li, L., and Desimone, R. (1991). A neural mechanism for working and recognition memory in inferior temporal cortex. Science 254, 1377-1379.

Oberauer, K. (2002). Access to information in working memory: exploring the focus of attention. J. Exp. Psychol. Learn. Mem. Cogn. 28, 411-421.

Palva, S., Kulashekhar, S., Hämäläinen, M., and Palva, J. M. (2011). Localization of cortical phase and amplitude dynamics during visual working memory encoding and retention. J. Neurosci. 31, 5013-5025. doi: 10.1523/JNEUROS CI.5592-10.2011.

Pashler, H. (1988). Familiarity and visual change detection. Percept. Psychophys. 44, 369-378.

Perlman, S. B., Huppert, T. J., and Luna, B. (2016). Functional near-infrared spectroscopy evidence for development of prefrontal engagement in working memory in early through middle childhood. Cereb. Cortex 26, 2790-2799. doi: 10.1093/cercor/bhv139.

Petrides, M. (1995). Impairments on nonspatial self-ordered and externally ordered working memory tasks after lesions of the mid-dorsal part of the lateral frontal cortex in the monkey. J. Neurosci. 15, 359-375.

Qiu, A., Mori, S., and Miller, M. I. (2015). Diffusion tensor imaging for understanding brain development in early life. Ann. Rev. Psychol. 66, 853-876. doi: 10.1146/annurev-psych-010814-015340

Reynolds, G. D., and Romano, A. C. (2016). The development of attention systems and working memory in infancy. Front. Syst. Neurosci. 10:15. doi: $10.3389 /$ fnsys.2016.00015

Riggs, K. J., McTaggart, J., Simpson, A., and Freeman, R. P. (2006). Changes in the capacity of visual working memory in 5- to 10-year-olds. J. Exp. Child Psychol. 95, 18-26. doi: 10.1016/j.jecp.2006.03.009

Ross-Sheehy, S., Oakes, L. M., and Luck, S. J. (2003). The development of visual short-term memory capacity in infants. Child Dev. 74, 1807-1822. doi: 10.1046/j.1467-8624.2003.00639.x

Sato, H., Hirabayashi, Y., Tsubokura, H., Kanai, M., Ashida, T., Konishi, I., et al. (2012). Cerebral hemodynamics in newborn infants exposed to speech sounds: a whole-head optical topography study. Hum. Brain Mapp. 33, 2092-2103. doi: $10.1002 / \mathrm{hbm} .21350$

Seeley, W. W., Menon, V., Schatzberg, A. F., Keller, J., Glover, G. H., Kenna, H., et al. (2007). Dissociable intrinsic connectivity networks for salience processing and executive control. J. Neurosci. 27, 2349-2356. doi: 10.1523/JNEUROSCI.5587-06.2007

Serences, J. T., Ester, E., Vogel, E., and Awh, E. (2009). Stimulus-specific delay activity in human primary visual cortex. Psychol. Sci. 20, 207-214. doi: 10.1111/j.1467-9280.2009.02276.x

Shimi, A., Kuo, B. C., Astle, D. E., Nobre, A. C., and Scerif, G. (2014). Age group and individual differences in attentional orienting dissociate neural mechanisms of encoding and maintenance in visual STM. J. Cogn. Neurosci. 26, 864-877. doi: 10.1162/jocn_a_00526

Short, S. J., Elison, J. T., Goldman, B. D., Styner, M., Gu, H., Connelly, M., et al. (2013). Associations between white matter microstructure and infants' working memory. NeuroImage 64, 156-166. doi: 10.1016/j.neuroimage.2012.09.021

Simmering, V. R. (2012). The development of visual working memory capacity during early childhood. J. Exp. Child Psychol. 111, 695-707. doi: 10.1016/j.jecp.2011.10.007

Thomason, M. E., Race, E., Burrows, B., Whitfield-Gabrieli, S., Glover, G. H., and Gabrieli, J. D. E. (2009). Development of spatial and verbal working memory capacity in the human brain. J. Cogn. Neurosci. 21, 316-332. doi: $10.1162 /$ jocn. 2008.21028

Todd, J. J., and Marois, R. (2004). Capacity limit of visual short-term memory in human posterior parietal cortex. Nature 428, 751-754. doi: 10.1038/nature02466

Tsujii, T., Yamamoto, E., Masuda, S., and Watanabe, S. (2009). Longitudinal study of spatial working memory development in young children. NeuroReport 20, 759-763. doi: 10.1097/WNR.0b013e32832aa975

Tsujimoto, S., Yamamoto, T., Kawaguchi, H., Koizumi, H., and Sawaguchi, T. (2004). Prefrontal cortical activation associated with working memory in adults and preschool children: an event-related optical topography study. Cereb Cortex 14, 703-712. doi: 10.1093/cercor/bhh030

von Allmen, D. Y., Wurmitzer, K., and Klaver, P. (2014). Hippocampal and posterior parietal contributions to developmental increases in visual short-term memory capacity. Cortex 59, 95-102. doi: 10.1016/j.cortex.2014. 07.010

Weiss, A. R., Nadji, R., and Bachevalier, J. (2016). Neonatal perirhinal lesions in rhesus macaques alter performance on working memory tasks with high proactive interference. Front. Syst. Neurosci. 9:179. doi: $10.3389 /$ fnsys.2015.00179

Wilcox, T., and Biondi, M. (2016). Functional activation in the ventral object processing pathway during the first year. Front. Syst. Neurosci. 9:180. doi: 10.3389/fnsys.2015.00180

Wilcox, T., Bortfeld, H., Woods, R., Wruck, E., Armstrong, J., and Boas, D. (2009). Hemodynamic changes in the infant cortex during the processing of featural and spatiotemporal information. Neuropsychologia 47, 657-662. doi: 10.1016/j.neuropsychologia.2008.11.014

Wilcox, T., Bortfeld, H., Woods, R., Wruck, E., and Boas, D. A. (2005). Using nearinfrared spectroscopy to assess neural activation during object processing in infants. J. Biomed. Opt. 10, 11010. doi: 10.1117/1.1852551

Wilcox, T., Bortfeld, H., Woods, R., Wruck, E., and Boas, D. A. (2008). Hemodynamic response to featural changes in the occipital and inferior temporal cortex in infants: a preliminary methodological exploration. Dev. Sci. 11, 361-370. doi: 10.1111/j.1467-7687.2008.00681.x

Wilcox, T., Haslup, J. A., and Boas, D. A. (2010). Dissociation of processing of featural and spatiotemporal information in the infant cortex. NeuroImage 53, 1256-1263. doi: 10.1016/j.neuroimage.2010.06.064

Wilcox, T., Hirshkowitz, A., Hawkins, L., and Boas, D. A. (2014). The effect of color priming on infant brain and behavior. NeuroImage 85, 302-313. doi: 10.1016/j.neuroimage.2013.08.045

Wilcox, T., Stubbs, J., Hirshkowitz, A., and Boas, D. A. (2012). Functional activation of the infant cortex during object processing. NeuroImage 62, 1833-1840. doi: 10.1016/j.neuroimage.2012.05.039

Zosh, J. M., and Feigenson, L. (2012). Memory load affects object individuation in 18-month-old infants. J. Exp. Child Psychol. 113, 322-336. doi: 10.1016/j.jecp.2012.07.005

Conflict of Interest Statement: The authors declare that the research was conducted in the absence of any commercial or financial relationships that could be construed as a potential conflict of interest.

Copyright $\odot 2016$ Fitch, Smith, Guillory and Kaldy. This is an open-access article distributed under the terms of the Creative Commons Attribution License (CC BY). The use, distribution or reproduction in other forums is permitted, provided the original author(s) or licensor are credited and that the original publication in this journal is cited, in accordance with accepted academic practice. No use, distribution or reproduction is permitted which does not comply with these terms. 